\section{"Quando um não quer, dois não brigam": um estudo sobre o não uso constante de preservativo masculino por adolescentes do Município do Rio de Janeiro, Brasil}

\author{
"It takes two to tango": \\ a study on inconsistent use of male condoms \\ by adolescents in Rio de Janeiro, Brazil
}

Kátia Geluda 1

Maria Lucia Magalhães Bosi 2,3

Antonio José Ledo Alves da Cunha 1

Anete Trajman 4,5

\footnotetext{
1 Instituto de Puericultura e Pediatria Martagão Gesteira, Universidade Federal do Rio de Janeiro, Rio de Janeiro, Brasil. 2 Faculdade de Medicina Universidade Federal do Rio de Janeiro, Rio de Janeiro, Brasil. 3 Núcleo de Estudos de Saúde Coletiva, Universidade Federal do Rio de Janeiro, Rio de Janeiro, Brasil. 4 Departamento de Medicina, Universidade Gama Filho, Rio de Janeiro, Brasil.

5 Escola de Medicina, Fundação TécnicoEducacional Souza Marques, Rio de Janeiro, Brasil.

Correspondência K. Geluda Instituto de Puericultura e Pediatria Martagão Gesteira, Universidade Federal do Rio de Janeiro. Rua Gustavo Sampaio 732 apto. 401, Rio de Janeiro, $R J$ 22010-010, Brasil. geluda@uol.com.br
}

\begin{abstract}
This study assessed gender-related aspects involved in the inconsistent use of male condoms by adolescents in Rio de Janeiro, Brazil. Four focus groups were conducted, two with each gender, two in a public school and two in a private school, totaling 34 participants, comparing gender and social status. The resulting material was analyzed using a critical interpretative approach. Among the emerging themes, "gender relations" were chosen, consisting of three dimensions: trust, submission, and initiative. Socalled unequal gender power was not detected in the adolescents' discourse, which however revealed an apparent inequality in negotiation and initiative in condom use. Differences between public and private schools were subtle. Some changes may be occurring in the field of adolescent sexual behavior. The results indicate the importance of channels for dialogue, taking into account the singularity of groups in order to establish intervention strategies adapted to subjects and different historical and cultural contexts.
\end{abstract}

Adolescent; Condoms; Sexually Transmitted Diseases; Acquired Immunodeficiency Syndrome

\section{Introdução}

A epidemia da AIDS, com prevalências que ainda crescem e incidências que se estabilizam, merece atenção da comunidade científica ${ }^{1}$. No mundo são, em média, 40 milhões de pessoas infectadas com HIV/AIDS. No Brasil, são 362.364 portadores de HIV/AIDS 2. O quadro é ainda mais preocupante quando nos remetemos aos jovens. Um terço da população mundial que vive com AIDS tem entre 15 e 24 anos ${ }^{3}$. No Brasil, até junho de 2004, entre os 41.274 adolescentes entre 13 e 24 anos com HIV/AIDS, 25.167 eram meninos e 16.107 meninas 2. De 2000 a 2002 observou-se uma inversão na relação homem x mulher 2. Em 2004, a relação era de 1:12.

O uso do preservativo é a única forma de prevenção contra as doenças sexualmente transmissíveis (DST)/AIDS e gravidez não planejada 4 . No entanto, apesar do aumento da freqüência do uso do preservativo entre jovens, o uso consistente ainda é infreqüente, principalmente nas relações eventuais 5 .

As pesquisas no campo da sexualidade nessa faixa etária têm privilegiado o comportamento individual como responsável pela vulnerabilidade em que se encontram os jovens 6 , numa perspectiva não raro descritiva que não contempla os aspectos subjetivos inerentes às práticas. O predomínio do paradigma positivista nos estudos relativos à saúde humana parece explicar o número reduzido de pesquisas 
voltadas à compreensão do uso do preservativo englobando dimensões simbólicas, sociais e culturais, imprescindíveis para o planejamento de intervenções adequadas aos diferentes segmentos 7 .

Dentre os aspectos ainda pouco explorados, a não inclusão das questões de gênero como mais um fator implicado na transmissão do HIV tem sido criticada ${ }^{8}$. As desigualdades entre os gêneros se expressam nos planos: político, cultural e sócio-econômico e seus efeitos emergem tanto no contexto macro como microssociológico.

Gênero é aqui entendido como um modo de ser e atuar diferenciado, decorrente de uma construção social e histórica de caráter relacional que se configura a partir das significações e da simbolização cultural das diferenças anatômicas 9. Gênero, uma das dimensões constitutivas das relações sociais e das identidades dos indivíduos, homens e mulheres, é ainda assumido por Barbosa 10 e Giffin 11 como categoria relacional e transversal, articulada às dimensões de classe social e cultural, de etnia e de gerações, que por si só não pré-determina diferenciais de vulnerabilidade. Essa concepção aplicada à esfera reprodutiva e de saúde permite relacionar os gêneros, assim como comparar as mulheres de diferentes classes sociais ou mesmo, de diferentes idades. Sobretudo quando atravessamos uma "transição de gênero”, na qual uma atualização ideológica da condição feminina faz-se refletir na condição masculina. Noutras palavras, mudanças em relação à identidade, papéis e poder de um gênero terá conseqüências sobre o outro gênero 11 .

No âmbito da temática aqui focalizada, a mulher, além de biologicamente mais vulnerável à infecção pelo HIV e outras DST, tem funções, responsabilidades e direitos diferentes daqueles atribuídos ao homem que variam de acordo com o contexto social. Essas diferenças nos papéis de gênero se associam a diferenças sociais e acarretam dificuldades específicas na negociação do método de prevenção das DST, ainda mais evidentes nas camadas sociais economicamente desfavorecidas 9 .

As questões de gênero revelam, assim, o efeito sinérgico de múltiplos determinantes de vulnerabilidade a que as mulheres estão submetidas 8 .

O lugar de submissão emocional e econômica ainda ocupado por um número expressivo de mulheres tem causas históricas e bem definidas 12. No Brasil, persiste uma cultura sexual tradicional, impregnada por uma visão dualista de gênero, onde o "machismo" é um fenômeno marcante, delegando ao homem atribu- tos de atividade, dominação, racionalidade, e à mulher de passividade, submissão e emoção 13 . A recomendação de uso do preservativo masculino nem sempre pode ser discutida e negociada antes da relação sexual, o que coloca a mulher, que precisa solicitar o seu uso, numa situação em que depende da anuência do parceiro, com valores e iniciativas masculinas que revelam preconceitos e produzem constrangimentos quando não se submetem às ações coercitivas e, muitas vezes, agressivas 6,12 .

Para jovens do sexo feminino, estar afetivamente envolvida, ter confiança, tempo de relacionamento, sentir medo de perder o parceiro e constrangimento pelas reações e discussões dolorosas e violentas com os companheiros dificultam a negociação do uso do preservativo 9,14,15,16.

Os conceitos de fidelidade, estabilidade, parceiro fixo e monogamia, conferem àquelas que exercem estas modalidades de parceria a sensação de sexo seguro e, resultam na decisão de não uso do preservativo, mesmo quando sabem da infidelidade do parceiro. Na literatura relativa ao tema evidencia-se que alguns jovens declaram fazer sexo ainda que não tenham preservativo na "hora da transa" 9,15,16,17. No entanto, numa postura diferenciada, também são relatadas tentativas de negociação no grupo adolescente 17 , ainda que persistam dificuldades em conversar sobre o uso do preservativo 15.

Ante os elementos brevemente expostos, nosso objetivo no presente estudo foi explorar aspectos relacionados ao gênero com o intuito de compreender o não uso constante do preservativo entre estudantes adolescentes, buscando contribuir para a fundamentação de propostas de ações diferenciadas que propiciem o sexo seguro neste segmento.

\section{Método}

A escolha da abordagem qualitativa para a realização desta investigação se justifica, em primeira instância, pela natureza do objeto, que supõe respostas múltiplas, que não poderiam ser expressas ou traduzidas por linguagem numérica, tampouco antecipadas por meio de variáveis demarcadas pelo pesquisador 19,20. Parte-se, assim, de uma postura heurística que, no plano ontológico, recusa o princípio da existência de uma realidade em si a ser coletada para, em lugar disso, reconhecer o caráter de construção em relação - portanto intersubjetiva-das informações.

No plano epistemológico tal postura reflete a renúncia a uma busca de objetividade e neutralidade, concebendo as técnicas como rela- 
ções sociais submetidas aos aspectos contextuais sócio-históricos que circunscrevem as demais relações. Partindo-se dessa concepção referente às técnicas de pesquisa, a aproximação aos dados empíricos deste estudo se deu por meio da realização de grupos focais 21 , com conteúdo registrado em fitas cassete, transcrito em momento posterior.

A amostra se delineou a partir de uma perspectiva de intencionalidade, como sugere Triviños 22 , refletindo os contornos do objeto amostra, portanto, teórica conforme designa Tesch 23 - e compreendeu 34 adolescentes que atendiam, tanto na totalidade como na singularidade, os requisitos necessários para compor o conjunto de informantes-chave da investigação.

Foram realizados quatro grupos focais, dois em escola pública, dois em escola privada, que no Brasil atendem a estratos sócio-econômicos distintos, separados por gênero, num total de 34 adolescentes entre 16 e 18 anos (média 16,7 \pm $0,7)$ sexualmente iniciados e que não faziam uso constante do preservativo, freqüentando o Ensino Médio.

Aqui cabe assinalar que ainda são poucos os trabalhos com esta temática entre adolescentes, provavelmente pela dificuldade do acesso aos jovens, em especial no ambiente escolar, devido a impedimentos, alguns deles vivenciados ao longo desta pesquisa como a recusa à implementação de técnicas qualitativas por parte de diretores de estabelecimentos de ensino privado do Rio de Janeiro e do Departamento Geral de Educação para o estudo do uso do preservativo 18.

Ante essas dentre outras dificuldades inerentes à investigação da temática focalizada em um estudo desta natureza desenvolvido em ambiente escolar, as instituições foram escolhidas levando-se em conta a viabilidade de realização do estudo, selecionando-se aquelas cujas direções assinaram a autorização para realização da pesquisa. Ao lado disso, foram cuidadosamente considerados os aspectos éticos inerentes à condução do estudo. Os responsáveis e os adolescentes também assinaram Termo de Consentimento Livre e Esclarecido. Para a seleção dos integrantes dos grupos focais, duas perguntas foram apresentadas por escrito (se eram sexualmente iniciados e se usavam sempre o preservativo) ao conjunto dos estudantes por um dos pesquisadores que entrou em todas as salas de aula com turmas presentes à escola no dia da sondagem. A privacidade dos informantes não foi, portanto, exposta ao grupo e à instituição, uma vez que o procedimento de respostas por escrito, recolhidas pela própria pesquisadora logo após a aplicação, permitiu que apenas a pesquisadora tivesse acesso às mesmas e à identidade dos informantes. Além disto, só responderam aqueles que consentiram, pois foi dada a eles a possibilidade de não responderem, caso não o quisessem.

Aos iniciados que não usavam preservativo foram entregues, posteriormente, os consentimentos livres e esclarecidos a serem assinados pelos responsáveis e pelos alunos. Considerando-se a temática - sexo inseguro, uso irregular de preservativo - ante o contexto sócio-familiar, o consentimento teve, também, o cuidado de preservar os adolescentes diante de seus pais, não declarando em nenhum momento o critério de seleção dos informantes.

Em relação ao contexto escolar, os selecionados foram chamados por meio de telefonemas efetuados de local externo a este espaço; portanto, dentre os alunos, nenhum deles ficou sabendo quem era ou não sexualmente ativo ou quem fazia uso constante do preservativo, exceto os participantes dos grupos focais. Os não selecionados também não ficaram sabendo do critério de inclusão nos grupos. Da mesma forma, como já referido, apesar das dificuldades impostas pela intermediação dos responsáveis em pesquisas relacionadas a temas como sexualidade, conforme descritas na literatura 18 , preservamos os adolescentes diante de seus pais, não transparecendo qualquer informação que os expusesse.

No interior dos grupos focais constituídos após todos esses cuidados éticos, procurou-se favorecer a interação e a explicitação das percepções, idéias, expectativas e sentimentos a partir das vivências, partindo-se de uma pergunta disparadora: "Todos/as sabem que a única forma de se prevenir contra a AIDS e outras DST é usar a camisinha. Todos/as vocês já tiveram relações sexuais e às vezes usaram a camisinha ou nunca usaram. Por que não usam sempre?". Durante as discussões, o pesquisador procurou intervir no sentido de reconduzir a discussão para o tema central e propor perguntas para que os sentidos do discurso fossem explicitados e desdobrados, numa atitude interativa intersubjetiva. A técnica de grupo focal exige dos participantes um desembaraço para articular idéias, dificultando a participação dos jovens mais tímidos. Inversamente, a exacerbação do exibicionismo, incentivada pela presença do grupo, pode ocorrer e idéias fantasiosas serem construídas. Torna-se difícil determinar se existe um consenso de opiniões ou se algum informante está abrindo mão de um pensamento individual para se adequar à opinião de ou- 
tros ou do que supõe ser a opinião da pesquisadora. Entretanto, a pesquisadora e seu assistente se eximiram de expressar julgamentos ou opiniões e cientes do limites da técnica, mantiveram-se atentos aos aspectos aqui referidos, considerando-os no momento do exercício hermenêutico, o que reduziu sobremaneira as limitações inerentes à técnica.

Em cada grupo, um assistente do pesquisador/facilitador anotava a discussão e supervisionava o funcionamento do gravador, embora não tenham participado das discussões que ocorreram em encontros com duração aproximada de uma hora e meia, em local onde a privacidade pôde ser garantida.

Na seqüência, procedemos a leitura exaustiva e repetida do material, ou, como afirmam Minayo 24 e Triviños 22, a leitura flutuante das transcrições das entrevistas, de maneira a permitir a nossa impregnação pelo sentido do "todo" de cada depoimento, bem como a identificação das unidades de significação, que indicam os vários "momentos" ou temas presentes nessas descrições 25 .

Dentro de uma postura metodológica fundamentada na tradição crítico-interpretativa 7, seguimos os passos para coleta e análise do material discursivo 26 .

As fitas gravadas foram transcritas pelos pesquisadores, procedimento que permitiu inserir comentários acerca do que foi dito e também sobre os silêncios, os não-ditos percebidos, das comunicações não-verbais e das reações do grupo abrangendo a fala nos planos $d i$ gital e analógico 27.

Em cada grupo, procurou-se encontrar as particularidades no nível intragrupal, isto é, as falas que se diferenciavam no interior de cada grupo. Foram observadas também as contradições e ambigüidades no discurso dos participantes. Em seguida, a leitura horizontal do material teve como objetivo buscar os elementos comuns e variantes intergrupais para se formular a estrutura do vivido, primeiro entre os tipos de estabelecimento escolar e depois entre os gêneros.

O exercício hermenêutico buscou ultrapassar as falas espontâneas dos informantes evitando recair na ilusão de transparência, entendida como a crença do pesquisador nas explicações correntes sobre as idéias e comportamentos dos atores, deixando-se iludir que o seu significado pode ser buscado apenas na consciência dos atores 28 . As temáticas foram estabelecidas para se contemplarem as dimensões e dinâmicas das relações estabelecidas, iniciando-se, então, o diálogo propriamente dito com o referencial teórico. Nessa etapa, adotamos a categorização retardada: núcleos de sentido encontrados a partir das falas com a incorporação gradual da teoria como caminho analítico 19, dialogando com diferentes domínios disciplinares, já que o próprio tema, a complexidade do ser humano e do conhecimento, reclama a convergência de saberes 29 .

A discussão que se segue busca apresentar o diálogo estabelecido com alguns elementos do universo semântico que o estudo permitiu recuperar. Com base nesse material, emergiram categorias que foram dispostas em torno de um eixo composto por cinco temas: a força do desejo; a sexualidade na cultura e a cultura da sexualidade; a dor real e a dor simbólica; as relações de gênero; e as informações. Discutiremos neste artigo as relações de gênero e suas dimensões: a confiança, a submissão e a iniciativa. Nele abordamos a percepção que cada membro do casal tem do outro, seus papéis nas negociações, sua autonomia e responsabilidades, aspectos em jogo na decisão de usar o preservativo.

O projeto de pesquisa n. 13/2002 foi aprovado pelo Comitê de Ética em Pesquisa do Instituto de Puericultura e Pediatria Martagão Gesteira, Universidade Federal do Rio de Janeiro.

\section{Compreendendo a questão}

\section{Quando um não quer, dois não brigam: as relações de gênero}

No estudo, a categoria empírica confiança revelou-se polissêmica - a confiança entre os parceiros - entendida como fidelidade, como expressão de amor e de consciência/responsabilidade - coexistindo os diferentes sentidos em um mesmo depoimento conforme ilustrado a seguir.

A fidelidade, entendida como relações monogâmicas, protegeria do risco de relações múltiplas. Os discursos elaborados indicam, principalmente para as meninas e as de escola pública, o dever da fidelidade, o que comumente sedimenta a auto-estima feminina. Existe a expectativa de que o amor e a fidelidade sejam plenamente correspondidos com a exclusividade sexual.

“... Eu só tenho um namorado, eu confio nele, eu tenho certeza de que ele não vai me trair. Eu também não vou. Por que ele vai procurar outra? (...) meu namorado tem certa responsabilidade comigo. Mas pode ser que não, ele pode trair minha segurança, mas espero que pelo menos ele tenha consciência: vou usar camisinha para não transmitir nada à garota [se ti- 
ver relações com outra]" (Graziela, escola pública).

Na dupla moral vigente em nossa sociedade, ser fiel parece ser uma condição feminina, enquanto a infidelidade masculina é tolerada 16. A maioria das adolescentes não menciona nem admite a infidelidade nos seus depoimentos, e acredita estar envolvida em relações monogâmicas onde não é preciso usar o preservativo.

De um modo geral, nas meninas, principalmente de escola pública, há a expectativa de encontrarem em seus respectivos parceiros a reciprocidade na confiança que depositam neles, o que parece possibilitar não se comprometerem com o uso do preservativo.

A confiança, baseada na fidelidade e na parceria fixa e única, dificulta pedir o uso da camisinha, pois a solicitação pode ser entendida como a revelação de ter "pulado a cerca", ser ativa ou acusar o outro de assim ter feito, contrariando as normas sociais 16,17,30. Esse critério para uso do preservativo se mostra difundido entre diferentes jovens como nos mostram as pesquisas com jovens em prostituição e detentos 31,32. Essa crença é preocupante, considerando-se que a transmissão do HIV por meios destes parceiros fixos, mesmo que por um curto período de tempo, tem infectado as mulheres 16,17,30.

Contudo, alguns depoimentos revelam um senso crítico na crença de fidelidade em ambos os gêneros, independente da classe. Entretanto, este senso não leva os jovens efetivamente ao uso constante do preservativo:

"Eu confiava mais, mas meu namorado se mudou pra São Paulo, desde maio. (...) Se ele vier agora, eu não tenho coragem de transar com ele sem camisinha porque ele deve ter 'dado' lá, eu não tenho coragem, mas antes tinha" (Ilana, escola pública).

"Eu não tenho esta confiança. Eu acho assim: do mesmo modo que eu posso trair ela com outra pessoa, ela pode trair e não falar nada e pegar essa doença" (Jaques, escola pública).

O confronto das colegas provoca a problematização do sentimento de confiança e fidelidade, mas ainda sobrepõe à racionalidade.

"Eu sei que é assim, a maioria das mulheres que tem, é casada, a maioria tem AIDS por confiar no marido. Mas se eu estou satisfazendo meu namorado, mesmo que ele transe com outra, põe a camisinha com a outra. (...) Mas eu confio, eu conheço a pessoa, (...) eu nunca parei para pensar realmente: será que ele pode estar com outra pessoa, será que ele pode estar me passando alguma doença? Não. Eu tenho confiança nele" (Graziela, escola pública).

Para os meninos, tanto os de escola pública como os de estabelecimentos privados, tanto a confiança como a fidelidade quase não se pronunciam porque provavelmente esperam que suas parceiras tenham este princípio que rege preferencialmente as mulheres. Aparentemente, a confiança se relaciona ao tipo de parceria, ainda que se possa encontrar, muito tenuamente, esta fala também nas meninas. Na classe de parceria eventual, encontram-se as meninas de programa ou "ficantes". No decorrer do grupo focal, talvez por se sentirem mais soltos para declarar o que realmente é a prática, pudemos perceber que os meninos, mesmo com as parceiras eventuais, nem sempre usam o preservativo.

“... Com a namorada, você conhece há bastante tempo, você adquire aquela confiança na menina. (...) Eu confio, mas se de repente a gente mal conhece, tem que usar camisinha. É de lei" (Roberto, escola pública).

Dos meninos e homens é aceito ter várias experiências sexuais, sem que haja necessariamente envolvimento afetivo. Também as meninas esperam que haja esta discriminação entre os parceiros. Quem usa preservativo é a "outra”, a pecadora, a prostituta, a "escolada" 16,33. Esta crença foi reforçada na medida em que os primeiros programas de intervenção 33 limitavam-se às mulheres envolvidas na prostituição ou ligadas a múltiplos parceiros sexuais, como se as mulheres monogâmicas estivessem imunes. A expectativa das meninas participantes desta pesquisa é, portanto, muito preocupante, pois não é correspondida pela prática revelada pelos meninos que nem sempre usam o preservativo quando mantêm relações sexuais com "ficantes" ou "mulheres da noite".

Confiança por conhecer o outro há muito tempo ou pela convivência familiar ou bairrista esteve presente nas declarações dos participantes dos quatro grupos, revelando crenças apontadas por Guimarães 34 , referentes a quem está fora do núcleo familiar - os periféricos ou desconhecidos, como os homossexuais, prostitutas, drogados - dever se proteger e apenas deles devemos nos proteger. A autora afirma que conhecimento como forma de confiança está presente em outros segmentos sociais e é o método preventivo mais usado para a AIDS 34. "Eu conheço ele/ela" tem como referência a família, esta, muitas vezes, instituição social que serve de eixo privilegiado para referendar comportamentos, principalmente nas classes populares (Duarte LFD, 1986, apud Guimarães 34).

Outra dimensão que surgiu nesse tema foi a submissão. Na situação do ato sexual, os meninos, principalmente os de escola pública, se sentem submetidos ao desejo das meninas de se entregarem ou terem relações. Com clareza, 
as falas apontam que, apesar do movimento deles ser ativo, pois a penetração é feita por eles, reconhecem a atividade da mulher, já que é ela quem permite ou não a iniciação sexual com a penetração; e que se elas recusassem a relação sem preservativo, teriam de aceitar.

"Se ela insistisse, eu usaria também. Neste caso, acho que a gente está submisso à mulher. Submisso. [os outros participantes concordam] Ela quem faz as preliminares, ela quem provoca este tesão. Se ela insistir na hora em usar a camisinha, com certeza usaria. (...) Você está forçando a barra, mas vai ser no dia e na hora em que ela quiser" (Rafael, escola pública).

Cabe ressaltar que os meninos participantes desses grupos focais iniciaram recentemente suas vidas sexuais, tiveram poucas relações e sua iniciação se deu com as namoradas ou "ficantes", e não com prostitutas, como era comum até poucas gerações atrás. Se sentem "agradecidos" pela oportunidade que elas deram a eles. Quando a parceira aceita iniciar-se sexualmente, a estréia para o menino é vivida como "uma luz no final do túnel”, uma "tábua de salvação".

As falas dos informantes contrariam a idéia promulgada que a questão de gênero não se encontra no plano da eqüidade, mas da desigualdade, com a submissão apontada como a posição que cabe às mulheres, na medida em que os homens têm sido apontados detentores do poder nas relações de gênero. Delineiam, talvez, um início de mudança na qual as mulheres estão numa posição um pouco mais privilegiada do que a até então ocupada.

Podemos nos referir ao que Giffin 11 considerou como uma transição de gênero, uma atualização ideológica dos gêneros. Se por um lado, a figura de uma nova mulher independente, que se responsabiliza e é responsabilizada não só pelo controle de sua fecundidade, mas por ter um trabalho próprio, pela provisão de renda e independência, promoveu a "libertação feminina" que inclui tanto conquistas como sobrecarga e superexploração, concomitantemente, alguns homens estão mais fragilizados e uma parcela ainda que pequena deles reivindica participar da esfera reprodutiva - da vida doméstica, do cuidado com filhos, da afetividade e aspiram a mudanças profundas nos estereótipos de masculinidade hegemônicos enquanto poder masculino. Esse estado atual pode explicar as visões mais igualitárias dos jovens da pesquisa, apontando para profundas transformações nas relações de gênero nessas novas gerações.

Duas falas se discriminaram das restantes em relação a esse assunto: uma aponta para uma idéia provavelmente dominante na nossa cultura e outra, que não privilegia nem homens nem mulheres, sugerindo transformações ou especificidades da faixa etária:

“A mulher não tem coragem, a mulher é sempre assim mais submissa ao homem. O homem está querendo e a mulher namorando sempre cede" (Valter, escola privada).

"Acho que não depende só dela, também. Se você não se autoconfiar, aí vai depender dela. Só existe ela no mundo? Está rolando um lance com ela, mas você não quer, quando um não quer, dois não brigam. Não é só ela não querer" (Jaques, escola pública).

A literatura sobre o assunto, 35,36 ao contrário, está impregnada pela idéia de passividade feminina, que atende ao desejo do outro e abnega o seu, com reforço social aos aspectos submissos e conformistas do exercício da sexualidade que dificultam a criação de um espaço onde a mulher possa se diferenciar dos desejos masculinos. Uma maior submissão é concernente a uma maior vulnerabilidade social daqueles que têm baixa renda, pela história de retraimento vivenciada por esta camada da população em nossa sociedade. A decisão de não usar o preservativo é uma "ordem".

Um fator que pode contribuir para uma maior igualdade na questão de gênero na opção de uso do preservativo pode ser a idade dos adolescentes, quando os padrões sociais de gênero, apesar de veiculados fortemente pela cultura, ainda não se enrijeceram como o observado nos adultos 33. O último depoimento acima parece apontar para as mudanças que talvez comecem a se processar na contemporaneidade.

Em relação a essa dimensão, apenas uma fala de menina retrata dificuldade de se impor e negociar o uso do preservativo. Mesmo assim ela consegue insistir e quando abre mão do uso é porque parece estar tomada pelo desejo sexual e, por isso, não querendo perder a oportunidade:

"Tem gente que não aceita. Tem vezes que eu peço e ele fala que não. Eu falo: '- Pô, não, cara, pelo amor de Deus, usa, é perigoso' (...) tem vezes que a gente discute. Às vezes faço assim mesmo, às vezes não. A vontade é muito grande [Rindo]. Não dá para controlar. O fogo é mais forte [Ela se abana com as mãos]" (Teresa, escola pública).

$\mathrm{Na}$ atualidade, quando a discussão de papéis tem fortalecido o sexo feminino, as meninas, ao que parece, já não se sentem na dinâmica relacional tão impedidas ou passivas durante um diálogo para a solicitação da camisinha quanto em tempos passados, embora muito recentes. 
Como última dimensão desse tema focalizaremos a questão da iniciativa no uso ou na solicitação de uso do preservativo, para uma melhor compreensão de como se dá a negociação entre o casal de jovens. Nos grupos realizados, a iniciativa de uso ou de solicitar o uso é muito precária para ambos os gêneros. Aconteceu para alguns nas primeiras relações, em lugares em que outros métodos não puderam ser utilizados ou, no caso dos meninos, quando eram parceiras desconhecidas ou conhecidas há pouco tempo.

Essa falta de iniciativa não nos parece ligada à dificuldade de adotar uma postura autônoma ou, para as meninas, ao silêncio em relação à vida afetiva. Os meninos raramente optam por utilizá-lo, não querem, mas não se recusam, quando solicitados. Transferem para elas a responsabilidade de pedir. Mas declaram que na vivência deles é raro uma menina solicitar, pois estão também ávidas pela "transa". As meninas, por sua vez, confirmam com suas declarações que não pedem porque não querem, não gostam. De forma geral, não sofrem recusa, quando solicitam.

"Se ele não oferecer, eu não vou pedir. Eu evito falar, se ele falar, eu evito. Eu não gosto” (Norma, escola pública).

“Tudo é questão de não perder a oportunidade. No caso, se ela exigisse, não tivesse como resolver a situação, usaria" (Roberto, escola pública).

No discurso dos meninos podemos perceber certa contradição. Se estes propõem que a decisão está $50 \%$ nas mãos de cada um, “depende das duas pessoas, se uma não quer ...”, transparecem ao mesmo tempo em que gostariam que elas se responsabilizassem pelas decisões. Por isto prefeririam que adotassem um método feminino.

Também as mulheres mais jovens e não casadas participantes da pesquisa de Goldstein 30 não tinham problemas em exigir a camisinha, se elas decidissem que queriam, sugerindo que provavelmente perdem o poder de exigir quando se casam, mesmo se o marido tem outras relações.

Como aponta Giffin 11, é preciso enfocar a questão de gênero numa perspectiva relacional e transversal, já que diferenças importantes e até contraditórias podem se explicitar entre mulheres e homens de diferentes classes sociais, etnias e gerações.

No entanto, a literatura salienta preponderantemente que nossa cultura é machista, e que a solicitação exigida a cada contato dificulta ainda mais a negociação feminina. As mulheres preferem correr o risco de se contaminar a perder a relação conjugal estável ou inicial. As expectativas delas são de que o homem tenha a iniciativa e controle a relação que está "nas mãos" deles. O preservativo é assunto de homem, é ele quem deve tê-lo. Quando pode, a mulher só solicita seu uso 9,37.

A falta de uso do preservativo por parte dos adolescentes pode estar vinculada ao estado em que se encontram depois de fazer uso de alguma droga e terem relações sexuais 38 . Rompendo com o que prevalece nas pesquisas sobre sexualidade, nos surpreendeu que por trás do uso de drogas estão os sentimentos de ansiedade e timidez. Estes sentimentos envolvem o ato de seduzir e a ameaça de serem rejeitados, que o discurso feminista, muitas vezes, não inclui como possíveis de serem vividos, muito menos admitidos pelos homens. Entretanto, foram declarados pelos meninos de escola privada. Os depoimentos abaixo revelam que por trás de toda onipotência e fortaleza masculina podem-se encontrar fragilidades:

“Eu estava no réveillon, estava doidão (...) rolou sem camisinha, sem nada. Se a pessoa bebe pra perder a timidez é porque é muito fechado. Bebe e quando vai transar, não vai pensar nisto daí, no depois, vai pensar aqui na hora, no agora" (Renato, escola privada).

\section{Conclusão}

Finalizamos este trabalho com a percepção de que algumas transformações podem estar acontecendo no campo das relações de gênero para o grupo estudado. Apesar do sentimento de confiança e seus inúmeros significados atravessarem as relações de gênero e interferirem nos comportamentos de proteção, persistindo a valoração das relações monogâmicas como fator protetor, a negociação e a iniciativa para o uso do preservativo, nessa faixa etária e nesse grupo sócio-econômico, não se mostram comprometidas pelas relações desiguais de poder como se observa em outros segmentos. Pelo contrário, em algumas falas, muitas vezes masculinas, transparece o poder de negociação, imposição e iniciativa das adolescentes.

O novo papel ativo que as adolescentes vêm assumindo junto aos parceiros, propiciandolhes a iniciação sexual, pode refletir mudanças nos papéis sociais contemporâneos da mulher e do homem. É possível, ainda, hipotetizar um início de mudança na qual as mulheres passariam a uma posição um pouco mais privilegiada do que a até então ocupada, sendo, contudo, necessárias novas análises de modo a constatar em que medida este achado se confirma. 
Na atualidade, quando a discussão de papéis tem fortalecido o sexo feminino, as meninas, ao que parece, já não se sentem na dinâmica relacional tão impedidas ou passivas durante um diálogo para a solicitação da camisinha quanto em tempos passados, embora muito recentes. Contudo, no presente estudo, a iniciativa de uso ou de solicitar o uso ainda é precária para ambos os gêneros.

Consideramos importante a atenção aos movimentos da sociedade para que não nos aferremos a padrões antigos que geram discursos feministas ou machistas que não acompanham possíveis transformações sociais. O novo e o estranho devem ser considerados.

Ao lado dos achados desta investigação, alguns limites devem ser igualmente levados em conta. Diversas questões não relacionadas ao gênero, também relevantes para a compreensão do problema, estavam fora do escopo deste artigo e não foram discutidas, o que, em parte, se deve ao recorte eleito. No plano metodológi-

\section{Resumo}

O objetivo deste estudo é analisar, numa perspectiva de gênero, aspectos envolvidos no não uso constante do preservativo masculino por adolescentes do Município do Rio de Janeiro, Brasil. Foram realizados quatro grupos focais com 34 estudantes adolescentes da rede de ensino público e privado, contrastando gênero e origem social. A análise intra e intergrupal do material discursivo fundamentou-se num enfoque críticointerpretativo. Dentre os temas identificados, abordamos "as relações de gênero", estruturando a exposição em torno de três dimensões: a confiança, a submissão e a iniciativa, que emergiram como eixos centrais. Os achados deste estudo ressaltam que a tão propalada desigualdade de poder entre os gêneros não se evidencia na fala dos adolescentes, ganhando, ao contrário, uma aparência de eqüidade na negociação e na falta de iniciativa para o uso do preservativo. São sutis as diferenças encontradas entre as escolas públicas e privadas. Mudanças podem estar ocorrendo neste campo do comportamento sexual entre adolescentes, o que ressalta a importância dos canais de diálogo, considerando-se a singularidade dos grupos na construção de estratégias adequadas aos atores sociais em seus contextos históricos e culturais.

Adolescente; Preservativos; Doenças Sexualmente Transmissíveis; Síndrome de Imunodeficiência Adquirida co, o fato de a pesquisa ter sido desenvolvida dentro da escola onde estudam e os participantes se conhecerem, pode constranger o participante a dar depoimentos, principalmente quando o assunto diz respeito às questões de sua intimidade e privacidade. Contudo, acreditamos que as falas construídas no diálogo estabelecido com os informantes expressam os valores dos grupos estudados.

Por último, reitera-se a necessidade de construção de práticas que possibilitem dar vazão aos sentimentos, dúvidas, medos, fantasmas que estão em jogo nas vivências de gênero e que favoreçam a escuta das demandas dos adolescentes, possibilitando que eles criem novas e diferentes modalidades de relação e vida sexual, atendendo à pluralidade dos modos de subjetivação na atualidade. A interlocução entre adolescentes dos dois gêneros que usam ou não o preservativo pode contribuir para novas produções de sentido, reorientando as ações direcionadas a esse grupo.

\section{Colaboradores}

K. Geluda participou da concepção do trabalho, pesquisa e levantamento bibliográfico, coleta, análise e interpretação dos dados, redação e revisão crítica da versão final do artigo. M. L. M. Bosi colaborou na concepção do estudo, bem como na orientação do trabalho de campo e na interpretação do material discursivo, na redação e revisão crítica, e leitura e aprovação da versão final do artigo. A. Trajman e A. J. L. A. Cunha contribuíram na concepção do trabalho, na análise e interpretação dos dados, na redação e revisão crítica, e leitura e aprovação da versão final do artigo.

\section{Agradecimentos}

Os autores agradecem à professora Regina Helena Simões Barbosa pelos comentários e sugestões oferecidos quando da leitura da versão preliminar deste artigo. 


\section{Referências}

1. Joint United Nations Programme on HIV/AIDS. Global summary of the HIV and AIDS epidemic. http: / / www.unaids.org/en/other/functionalities/ViewDocument.asp?href=http\%3a\%2f\%2fgva-doc-owl\% 2 fWEBcontent $\% 2$ fDocument $\% 2$ fpub\%2fEpidemiology\%2fSlides02\%2fEpicore2003_en\%26\%2346\%3b.ppt (acessado em 01/ Abr/2004).

2. Ministério da Saúde. Dados epidemiológicos Aids. Boletim Epidemiológico Aids e DST 2005; Ano I, n. 1 - 01ạ-26a semanas epidemiológicas janeiro a junho de 2004. p. 25-34.

3. United Nations Children's Fund/Joint United Nations Programme on HIV/AIDS/World Health Organization. Young people and HIV/AIDS: opportunity in crisis. New York: United Nations Children's Fund; 2002.

4. Kaplan DW, Feinstein RA, Fisher MM, Klein JD, Olmedo LF, Rome ES, et al. Condom use by adolescents. Pediatrics 2001; 107:1463-9.

5. Paiva V, Venturi G, França-Júnior L, Lopes F. 2 Uso de preservativos: Pesquisa Nacional MS/ IBOPE, Brasil 2003. http://www.aids.gov.br (acessado em 02/Mar/2004).

6. Paicheler G. General population and HIV prevention: from risk to action. Cad Saúde Pública 1999; 15 Suppl 2:93-105.

7. Bosi MLM, Mercado-Martinez FJ. Introdução notas para um debate. In: Bosi MLM, MercadoMartinez FJ, organizadores. Pesquisa qualitativa de serviços de saúde. Rio de Janeiro: Editora Vozes; 2004. p. 23-71.

8. Parker R, Camargo Jr. KR. Pobreza e HIV/AIDS: aspectos antropológicos e sociológicos. Cad Saúde Pública 2000; 16 Suppl 1:89-102.

9. Grimberg M. Sexualidade y relaciones de género: una aproximación a la problemática de la prevención al VIH-SIDA en sectores populares de la ciudad de Buenos Aires. Cuad Méd Soc 1999; 75:65-76.

10. Barbosa RHS, Giffin K. Juventude, saúde e cidadania: uma pesquisa/ação com jovens da Maré. Cad Saúde Colet (Rio J) 2005; 13:649-72.

11. Giffin K. Pobreza, desigualdade e eqüidade em saúde: considerações a partir de uma perspectiva de gênero transversal. Cad Saúde Pública 2002; 18:103-12.

12. Vermelho LL, Barbosa RHS, Nogueira AS. Mulheres com Aids: desvendando histórias de risco. Cad Saúde Pública 1999; 15:369-79.

13. Giffin K. Violência de gênero, sexualidade e saúde. Cad Saúde Pública 1994; 10 Suppl 1:146-55.

14. Deslandes SF, Mendonça EA, Caiaffa WT, Doneda D. As concepções de risco e de prevenção segundo a ótica dos usuários de drogas injetáveis. Cad Saúde Pública 2002; 18:141-51.

15. Taquette SR, Ruzany MH, Meirelles Z, Ricardo I. Relacionamento violento na adolescência e risco de DST/AIDS. Cad Saúde Pública 2003; 19:143744.

16. Paiva V, Peres C, Blessa C. Jovens e adolescentes em tempo de Aids: reflexões sobre uma década de trabalho de prevenção. Psicol USP 2002; 13:5578 .
17. Vieira NFC, Paiva TCH, Sherlock MM. Sexualidade, DST/Aids e adolescência: não quero falar, tenho vergonha. DST J Bras Doenças Sex Transm 2001; 13:46-51.

18. Geluda K, Bisaglia JB, Moreira V, Maldonado BM, Cunha AJLA, Trajman A. Third-party informed consent in research with adolescents: the good, the bad and the ugly. Soc Sci Med 2005; 61:985-8.

19. Creswell JW. Research design: qualitative and quantitative approaches. London: Sage Publications; 1994.

20. Uchimura KY, Bosi MLM. Qualidade e subjetividade na avaliação de programas e serviços de saúde. Cad Saúde Pública 2002; 18:1561-9.

21. Morgan DL. The focus group guidebook. Thousand Oaks: Sage Publications; 1998. (The Focus Group Kit, 1).

22. Triviños ANS. Introdução à pesquisa em ciências sociais: a pesquisa qualitativa em educação. São Paulo: Editora Atlas; 1990.

23. Tesch R. Qualitative research: analysis, type and software tools. New York: The Falmer Press; 1995.

24. Minayo M.C. O desafio do conhecimento: pesquisa qualitativa em saúde. São Paulo: Editora Hucitec/Rio de Janeiro: ABRASCO; 1992.

25. Martins J, Bicudo MAV. A pesquisa qualitativa em psicologia. São Paulo: EDUC; 1988.

26. Amatuzzi MM. Apontamentos acerca da pesquisa fenomenológica. Estud Psicol (Campinas) 1996; 13:5-10.

27. Watslawsky P, Beavin HJ, Jackson DD. A pragmática da comunicação humana: um estudo dos padrões, patologias e paradoxos da comunicação. São Paulo: Cultrix; 1997.

28. Bourdieu P. A construção do objeto. In: Bourdieu P, Chamboredon JC, Passeron JC, organizadores. Ofício de sociólogo. 5a Ed. Petrópolis: Editora Vozes; 2004. p. 45-72.

29. Petraglia IC. O ser e o saber. In: Morin E, organizador. A educação e a complexidade do ser e do saber. Petrópolis: Editora Vozes; 1995. p. 39-66.

30. Goldstein D. O lugar da mulher no discurso sobre AIDS no Brasil. In: Galvão J, Parker R, organizadores. Quebrando o silêncio: mulheres e AIDS no Brasil. Rio de Janeiro: Relume-Dumará/Associação Brasileira Interdisciplinar de AIDS/Instituto de Medicina Social, Universidade do Estado do Rio de Janeiro; 1996. p. 137-52.

31. Simon CP, Silva RC, Paiva V. Prostituição juvenil feminina e a prevenção da Aids em Ribeirão Preto. Rev Saúde Pública 2002; 36:88-95.

32. Peres CA, Paiva V, Silveira F, Peres RA, Hearst N. Prevenção de Aids com adolescentes encarcerados em São Paulo, SP. Rev Saúde Pública 2002; 36:76-81.

33. Parker R, Galvão J. Introdução. In: Galvão J, Parker R, organizadores. Quebrando o silêncio: mulheres e AIDS no Brasil. Rio de Janeiro: RelumeDumará/Associação Brasileira Interdisciplinar de AIDS/Instituto de Medicina Social, Universidade do Estado do Rio de Janeiro; 1996. p. 7-16.

34. Guimarães CD. “Mas eu conheço ele!”: um método de prevenção. In: Galvão J, Parker R, organizadores. Quebrando o silêncio: mulheres e AIDS 
no Brasil. Rio de Janeiro: Relume-Dumará/Associação Brasileira Interdisciplinar de AIDS/Instituto de Medicina Social, Universidade do Estado do Rio de Janeiro; 1996. p. 169-80.

35. Barbosa RM, Villela WV. A trajetória feminina da AIDS. In: Galvão J, Parker R, organizadores. Quebrando o silêncio: mulheres e AIDS no Brasil. Rio de Janeiro: Relume-Dumará/Associação Brasileira Interdisciplinar de AIDS/Instituto de Medicina Social, Universidade do Estado do Rio de Janeiro; 1996. p. 17-32.

36. Galvão MTG, Ramos-Cerqueira ATA, Ferreira MLSM, Souza LR. Razões do não uso do preservativo masculino entre pacientes com infecção ou não pelo HIV. DST J Bras Doenças Sex Transm 2002; 14:25-30.
37. Santos NIS, Minhoz R. A AIDS entre as mulheres: reflexões sobre seus depoimentos. In: Galvão J, Parker R, organizadores. Quebrando o silêncio: mulheres e AIDS no Brasil. Rio de Janeiro: Relume-Dumará/Associação Brasileira Interdisciplinar de AIDS/Instituto de Medicina Social, Universidade do Estado do Rio de Janeiro; 1996. p. 115-35.

38. Tremura FDA. O adolescente em conflito com a lei e as drogas. In: Congresso Internacional de Psicanálise e suas Conexões, organizador. O adolescente e a modernidade. Rio de Janeiro: Companhia de Freud; 1999. p. 255-61.

Recebido em 06/Jan/2005

Versão final reapresentada em 08/Nov/2005 Aprovado em 19/Dez/2005 